\title{
CONEXIONES FILIALES Y TRANSVERSALIDADES FEMENINAS: BELÉN MONEO FEDUCHI, MARISA SÁENZ GUERRA Y CRISTINA VALLEJO LLOPIS
}

\author{
FILIAL CONNECTIONS AND FEMININE TRANSVERSALITIES: BELÉN MONEO \\ FEDUCHI, MARISA SÁENZ GUERRA AND CRISTINA VALLEJO LLOPIS \\ Josenia Hervás* \\ Universidad de Alcalá de Henares \\ Silvia Blanco-Agüeira** \\ CESUGA-Universidad San Jorge
}

\section{Resumen}

Mujeres arquitectas, pero también hijas, hermanas, madres o esposas, nos permiten analizar las conexiones temporales, estéticas y materiales que se han producido en un ambiente de proximidad natural al mundo de la vanguardia del mobiliario y del interiorismo en España. En el caso de Belén Moneo, debemos señalar que en colaboración con Jeff Brock, ha dado soporte a la intervención de Rafael Moneo en el Museo de Arte Moderno y Arquitectura de Estocolmo (1991/98). Por su parte, Marisa Sáenz Guerra y su hermano Vicente también tuvieron el privilegio de trabajar con Francisco Javier Sáenz de Oíza en diversos proyectos y direcciones de obra. Finalmente, Cristina Vallejo Llopis ha colaborado con su padre en la dirección de obra de varios edificios, pero su conexión más estrecha con su progenitor, se halla en la silla Almería (1959), de estructura metálica, con asiento y respaldo encordado con esparto.

Palabras clave: mobiliario, diseño, arquitectura, Belén Moneo, Marisa Saénz, Cristina Vallejo.

\section{Abstract}

These creative women with filial attachments as well as professional linkages between the architecture and the world of design will enable us to analyse the temporal, aesthetic and material connections produced in an environment of close familiarity with the world of avant-garde furniture and interior design in Spain. In the case of Belén Moneo, we must point out that in collaboration with Jeff Brock, he has cooperated in Rafael Moneo's intervention at the Museum of Modern Art and Architecture in Stockholm (1991/98). On her

\footnotetext{
*E-mail: jhervasheras@colaboradorst.es

**E-mail: sblanco@usj.es
}

Financiación: Este artículo es resultado del proyecto de investigación "Mujeres en la cultura arquitectónica (pos)moderna española, 1965-2000”, con código PGC2018-095905-A-I00, y financiado por el Ministerio de Ciencia e Innovación del Gobierno de España y los Fondos Feder de la Unión Europea. 
side, Marisa Sáenz Guerra and her brother Vicente, also had the privilege of working with Francisco Javier Sáenz de Oíza on various projects and construction management. Finally, Cristina Vallejo Llopis has collaborated with her father in the project management of several buildings, but her closest connection with her father is settled in the Almería chair (1959), a string furniture made of metal structure and esparto grass.

Keywords: furnishement, design, architecture, Belén Moneo, Marisa Saénz, Cristina Vallejo.

\section{Las diseñadoras españolas: ausencias y referentes}

La relación entre arquitectos y diseñadores industriales se vuelve fecunda en España a partir de los años cincuenta, gracias a la llegada de modelos internacionales, a la creación en 1957 de instituciones como la SEDI (Sociedad de Estudios para el Diseño Industrial), y al desarrollo de una línea doméstica que seguía de cerca los aspectos formales de los modelos importados. Se promovieron además desde el Ministerio de Vivienda, en los años inmediatamente posteriores, concursos de mobiliario y exposiciones que consolidaban la presencia del diseño moderno en atmósferas domésticas. Incluso utilizaba organismos dependientes de él, como la EXCO (Exposición permanente e Información de la Construcción), que realizó una exposición y un concurso de mueble económico entre 1961 y 1962.

En los sucesivos pabellones españoles para las exposiciones internacionales, como la celebrada en Bruselas en 1958, se contó asimismo con la participación de equipos multidisciplinares que atendían a todas las escalas del diseño y proyectaban hacia el exterior las ideas más novedosas que se estaban desarrollando en España en ese sentido. Nombres como los de Carlos de Miguel, Luis Feduchi, Miguel Milá o Javier Carvajal se situaban en primera línea. Además de la repercusión individual de su obra, mostraban las posibilidades de una disciplina emparentada con la arquitectura, capaz de completar los espacios del habitar.

El diseño de interiores, como profesión, estaba vinculado a las Escuelas de Artes Aplicadas y Oficios Artísticos. Con el Decreto 2127, promulgado el 24 de julio de 1963, se regularon, entre otros, los estudios de diseño industrial, delineación, decoración y arte publicitario convirtiéndolos en especialidades independientes que se adaptaron al progreso científico y técnico, así como a las demandas de la sociedad. Con esta reforma del sistema de enseñanza de diseño, sería esperable una mayor presencia de tituladas que impulsase el desarrollo artístico en los nuevos ámbitos profesionales. Sin embargo, pese a lo que podría considerarse un contexto aparentemente más propicio, apenas surgen nombres femeninos ni su presencia es significativa en la producción de piezas pequeñas y del equipamiento del hogar. Las primeras arquitectas tituladas en España tampoco parecen haberse sumergido en especialidades como el diseño textil o de interiores, ni consta que hayan realizado una formación específica en ese itinerario alternativo. 
Resulta sorprendente este olvido o indiferencia, pues la posibilidad de dibujar planos y dedicarse al mundo de la decoración, sí se consideraban actividades posibles para el género femenino en la centuria pasada. De hecho, uno de los puntos importantes a tratar en el X Congreso Internacional de Arquitectos, celebrado en Bruselas en septiembre de 1922, fue el de 'la mujer arquitecto'. El representante español, Luis María Cabello y Lapiedra, pedía no cerrar las puertas de la práctica arquitectónica al género femenino, argumentando que, aunque el ejercicio de la profesión podría no ser adecuado debido a ciertos requerimientos físicos, las labores de delineación y decoración podrían ser desempañadas sin problemas por la 'compañera del hombre':

Podrá argumentarse, con mayor o menor fundamento, que el ejercicio de la profesión, al tener que trepar por andamios y escaleras, no será adecuado a las condiciones físicas y la indumentaria del sexo; pero lo que no admite duda es que la práctica del dibujo, el estudio del decorado, la misma disposición y traza de los planos [...] puede desempeñarlos la compañera del hombre en muy favorables condiciones, y se hallan dentro de sus aptitudes y cualidades. ${ }^{2}$

Las aptitudes y cualidades femeninas tenían a principios de los años veinte un número limitado de posibilidades. Las condiciones físicas de la mujer eran un argumento para tabular sus acciones. Por último, su vestimenta, que restringía sus movimientos no ayudaba a transmitir una idea de independencia y de seguridad. Pero cuarenta años después, las mujeres españolas ya empezaban a tener mecanismos de formación en las Escuelas de Artes y Oficios y en los centros específicos de enseñanzas artísticas, lo que les permitía lanzarse al mundo profesional. Solo una década antes, el discurso oficial de la Sección Femenina de la Falange Española situaba como principales proyectos vitales para las mujeres españolas el matrimonio y la maternidad. ${ }^{3}$

Con todo, a mediados del siglo XX todavía se estigmatizaba el interiorismo como una salida laboral de carácter marcadamente femenino. De hecho, se crearon escuelas segregadas por sexos como Elisava, fundada en Barcelona en 1961. En palabras de un antiguo director del centro, Ramón Benedito: "El objetivo inicial era dar una respuesta moderna y con visión de futuro a las mujeres que podían ejercer estudios como los de interiorismo". ${ }^{4}$ La que posteriormente se convertiría en la primera escuela de diseño de España, comenzó su andadura impartiendo estudios relacionados con los jardines de infancia y con la jardinería, es decir, nació como una institución femenina.

El diseño industrial era pues un ámbito tradicionalmente masculino en las décadas de los años sesenta y setenta. Además, buena parte del diseño de mobiliario estaba realizado por arquitectos varones o colectivos de profesionales en los que se encontraba algún arquitecto. La generación de jóvenes creadoras que comenzaron su ejercicio profesional tras formarse durante esa etapa no disfrutó de modelos cercanos, siendo las diseñadoras extranjeras el espejo en el que mirarse. No es extraño por tanto que para Lola Castelló —una de las pioneras en el diseño de mobiliario en España-, Sonia Delaunay fuera, junto a Ray Eames, su referente. ${ }^{5}$ 
Sonia Delaunay fue una mujer que supo transitar por todos los recovecos que le permitió la sociedad. Sus obras son completamente transversales, de manera que compaginaba su labor creativa, fuera y dentro de su tienda madrileña de decoración interior y moda Casa Sonia, con la intervención en espacios arquitectónicos y con su labor de copista en el Museo del Prado. ${ }^{6}$ Nunca abandonó su actividad como artista, pero supo aunar la labor de pintora y diseñadora con el ejercicio comercial. Para ella no existían obras de arte menores o mayores, por ello, además de sus pinturas y proyectos de interiores, diseñó vestuario, textiles para grandes firmas, o el acabado del Citroën B-12 en 19257, sin olvidar sus objetos de porcelana de Limoges.

Lola Castelló, al igual que Sonia Delaunay, supo compaginar la labor de diseñadora con el ejercicio comercial. A sus primeros diseños con el grupo NUC, una serie de muebles infantiles denominados Trilátera, siguieron la silla Nit, la silla Sis o la mesa Carmen, muchos de ellos ya fabricados tras la constitución de la empresa de mobiliario Punt Mobles en 1980, por la que recibió en 1997, junto a Vicent Martinez, el Premio Nacional de Diseño. ${ }^{8}$

En este sentido, las diseñadoras establecidas en España destacan por su faceta de empresarias. Castelló no fue un caso aislado. Nani Marquina lanzó su marca de diseño, creación y distribución de alfombras en 1987. Nancy Robbins, interiorista estadounidense, abrió en 1984 una tienda de mobiliario son su nombre y comenzó a desarrollar su trabajo como diseñadora. Así pues, los años ochenta son el punto de despegue para que comiencen a emerger las primeras figuras femeninas, sobre todo al vincularse a iniciativas potenciadas por un carácter colectivo de trabajo. La editora de productos catalana Santa \& Cole, a pesar de reflejar sólo los apellidos de dos de sus tres miembros fundadores, contó desde el inicio con Nina Masó, que junto a Javier Nieto Santa y Gabriel Ordeig Colé, creaban en 1985 la marca. ${ }^{9}$ Es difícil dilucidar si estaban camufladas, ocultas o no ejercían la profesión, pero lo cierto es que la historiografía no ha reflejado la presencia de mujeres con nombre propio en un entorno ligado a la industria española, a diferencia de las que ya sí destacaban en instituciones europeas pioneras del diseño. Hubo que esperar casi medio siglo en España para espantar las ideas de debilidad y falta de racionalidad del diseño femenino, perpetuadas por textos tan célebres como Ornamento y delito:

Loos critiqued everything from teapots to shoes, famously found that the ornament of design being criminal, primitive, degenerated and most importantly, erotic and feminine ${ }^{10}$.

\section{El diseño en España y su divulgación, 1960-1985}

En los años del desarrollismo español, donde el turismo era una empresa en auge, encontramos a constructoras como Huarte, con su división de mobiliario a través de la empresa $H$ muebles, perfectamente organizadas y coordinadas con arquitectos de reconocido prestigio que surtían toda la cadena. Ellos diseñaban y dirigían las obras de los hoteles y la empresa construía y amueblaba con el asesoramiento de estos profesionales. Los ejemplos de José Antonio Coderch en el Hotel del Mar; Francisco Javier Sáenz de Oíza con Juan Daniel Fullaondo en 
Ciudad Blanca (Mallorca); José Antonio Corrales y Ramón Vázquez Molezún en el Hotel Galúa (La Manga del Mar Menor) o Fernando Higueras con Cesar Manrique en el Hotel las Salinas (Lanzarote) son ilustrativos. ${ }^{11}$

En este campo de acción, las mujeres — tanto las arquitectas como las diseñadoras - no tuvieron especial notoriedad. Tampoco existió nunca una Werkbund española, una organización a nivel nacional que aunase a diseñadores, artistas, arquitectos e ingenieros para que cooperaran con las industrias del país. La arquitecta Marisa Sáenz Guerra, que entrevistaba a Juan Huarte en el año 2000, reflejó por escrito cómo este actuaba en ocasiones de mecenas, manteniendo veladas de madrugada, regadas con alcohol, en las que reunía a arquitectos, artistas y críticos de arte. Semejantes modelos de interacción, en los que las mujeres quedaban excluidas por esa época, no impidieron la escasa interactuación entre los profesionales de las distintas disciplinas. Huarte rememoraba la extrañeza de su ingeniero Fernández Casado ante las demandas de Oíza para la materialización de su proyecto Torres Blancas: "No hay forma de entenderse, no consigo que me diga cómo es la cosa para que yo pueda calcular el hierro, sino que quiere que surja el edificio como una cosa del ingeniero y arquitecto juntos, trabajando para ver cómo tiene que ser la forma". ${ }^{12}$

En 1960, el empresario Juan Huarte, a través de la empresa H Muebles, organizó un concurso que pretendía fomentar la industrialización en el diseño de mobiliario. El concurso H Muebles otorgaba varios premios: a una silla y una butaca ligera por un lado, y por otro lado, a una mesa de comedor. Las piezas ganadoras debían ser fácilmente reproducibles por la industria. El jurado estuvo formado exclusivamente por hombres ${ }^{13}$, entre los ganadores, solo aparece un nombre de mujer. La pintora asturiana Amparo Cores Uría surge en el apartado de accésits, siendo esposa y hermana respectivamente de los vencedores en la categoría de mesa de comedor, Jesús de la Sota y José Ramón Cores. Las mujeres empiezan pues tardíamente a ser consideradas como productoras visibles de artes decorativas con funciones domésticas, autoras de creaciones susceptibles de ser reproducibles por parte de la industria. Con todo, su presencia continúa siendo la excepción y su ratificación es más factible si se produce dentro del marco familiar, o en conexión directa con su pareja, padre o hermanos.

En 1960 surgía en Barcelona la Asociación de Diseño Industrial, ADIFAD, cuyo principal motor desde su creación han sido los Premios Delta, una plataforma de reconocimiento público, tanto a la labor de los diseñadores industriales como de las empresas productoras. Desde su primera edición en 1961, ha habido un desequilibrio de género entre los galardonados, destacando en las primeras ediciones apenas los nombres de María Rosa Ventós (1961) y Mireia Riera (1975).

Precisamente, Mireia Riera formó parte de la escena de vanguardia barcelonesa, aportando productos que resolviesen problemas funcionales. Junto a Oriol Bohigas, Miguel Milá, Oscar Tusquets, Lluís Clotet y Anna Bohigas, entre otros, se unió para desarrollar mobiliario y accesorios innovadores. Las influencias estéticas de este grupo provenían fundamentalmente de arquitectos milaneses, pero también de los grandes pioneros europeos, convirtiendo las atrevidas soluciones y las reediciones de piezas icónicas en imagen identificativa de la causa. Tras su éxito, el proyecto se renombró como Bocaccio Diseño 
(BD), trazando como claro objetivo la producción y divulgación del diseño contemporáneo. Cuando se desplegó la distribución de los productos más allá de Cataluña, el espacio de venta en Madrid de esta editorial de muebles tuvo al frente tres mujeres: inicialmente Belén Feduchi e Isabel Lantero y posteriormente a Luz Sánchez Muro' ${ }^{14}$. De esta forma, la empresa BD Madrid abría sus puertas en 1977, en pleno barrio de Salamanca, inaugurando así una etapa de fuerte labor didáctica alrededor del mueble de vanguardia. Escenario de exposiciones y montajes de artistas de renombre, la tienda no solo era el ambiente propicio para mostrar investigaciones experimentales o revolucionarias, sino también un centro de divulgación y una consultoría para cada cliente, al que se le trasladaba desde el valor del diseño hasta el aspecto creativo.

La nueva generación de diseñadoras que surgió en los años ochenta pudo realizar individualmente o en grupo, diferentes encargos que abarcaban desde la arquitectura al diseño gráfico e industrial. Marisa Gallén, Premio Nacional de Diseño 2019 y cofundadora del colectivo La Nave, activo en Valencia desde 1984 a 1991, podría ser un exponente claro de ello:

La Nave se convirtió en símbolo de modernidad. Fuimos un coworking 'avant la lettre'. Nos unimos para tener un espacio y posibilidades mayores de las que hubiéramos tenido trabajando individualmente. Para determinados proyectos hacíamos equipos, pero fundamentalmente compartíamos un espacio y una filosofía. Éramos un grupo variopinto y todos aprendimos mucho. ${ }^{15}$

Carlos Bento, el único arquitecto del grupo La Nave, también lo rememora como una experiencia enriquecedora:

Esos años, de 1984 a 1990, trabajé con total libertad y desarrollé cuanto pude mi creatividad. En La Nave no teníamos jefes ni horario. Los encargos llegaban y según de qué se trataba, se formaban grupos de trabajo de forma no preestablecida. Cada uno iba un poco a la suya, pero compartíamos espacio con lo que nos supervisábamos de forma natural unos a otros. Tuve la suerte de encontrar un grupo de gente estupenda, con la que conecté divinamente, a pesar de nuestras enormes diferencias en muchos otros aspectos. Adquirimos prestigio y fama internacionales. ${ }^{16}$

No es por tanto aventurado afirmar que los años ochenta marcaron una nueva etapa tanto para las arquitectas como para diseñadoras en nuestro país. Podían participar en proyectos con sus compañeros de profesión y se les abrían nuevas vías de trabajo, solas o acompañadas. Juventud, efervescencia cultural y ganas de afrontar una nueva época democrática. El trabajo de las diseñadoras españolas, que se vieron reducidas inicialmente al Arts and Crafts y a las especialidades «blandas» ${ }^{17}$, cobró a partir de los años ochenta un nuevo interés. Por otro lado, arte y técnica, tuvieron en sus tareas de difusión y comercialización un marcado carácter femenino. 


\section{Efervescencia de creadoras}

El ámbito más técnico, como el de la arquitectura, supondrá la fuente de procedencia de numerosos diseñadores industriales. Sin embargo, las mujeres arquitectas no se sumergirán en esa labor al estar menos próximas a la infraestructura más poderosa de la industria, por lo que sus propuestas eran más bien diseños puntuales para un encargo concreto y no prototipos que fueran a fabricarse en grandes cantidades y a colocarse en el mercado ${ }^{18}$. En las décadas finales del siglo XX, la evolución política y social, y el cada vez mayor acceso a las escuelas de arquitectura, conseguirá que nos encontremos con el ejemplo de arquitectas españolas, que además de escalar andamios, subir escaleras y dirigir obras, también se han dedicado al estudio y creación de pequeñas piezas integradas en la arquitectura. Mujeres creadoras relacionadas con el mundo del diseño, con estrechos vínculos filiales a la vez de profesionales, que nos permiten realizar el análisis y las conexiones temporales, estéticas y materiales producidas durante la segunda mitad del siglo XX, en un ambiente de proximidad familiar con el mundo del mobiliario de vanguardia y del interiorismo en España.

En el caso de Belén Moneo, debemos señalar que su colaboración con Jeff Brock ha dado soporte a proyectos paternos, como el Museo de Arte Moderno y Arquitectura de Estocolmo (1991/98), lo que le permitió diseñar lámparas y bancos para dicho espacio cultural. Por otra parte, Marisa Sáenz Guerra también tuvo el privilegio de trabajar con su padre y su hermano Vicente en diversos proyectos y direcciones de obra. El edificio para la Fundación Museo Jorge Oteiza (1995/2003), fue una inolvidable obra para su hija, que recordaba cómo Francisco Javier Sáenz de Oíza pudo apreciar toda la estructura acabada del museo antes de morir; estructura que sirvió de inspiración para la creación de la silla para la casa-taller y el salón de actos. Finalmente, la arquitecta Cristina Vallejo Llopis ha colaborado con su padre en la dirección de obra de varios edificios, como la Escuela de Hostelería de Alcalá de Henares (1991), pero su conexión más estrecha con su progenitor se halla en la silla Almería (1959), de estructura metálica, con asiento y respaldo encordado con esparto.

Los ejemplos de Belén Moneo Feduchi, Marisa Sáenz Guerra y Cristina Vallejo Llopis, hijas de Rafael Moneo Vallés, Francisco Javier Sáenz de Oíza y Antonio Vallejo Acevedo respectivamente, nos permitirán establecer intercambios generacionales, aportar visibilidad a trayectorias poco conocidas ${ }^{19}$, así como poner de manifiesto la transversalidad de una profesión en femenino y la importancia del mueble en la conformación del espacio arquitectónico total.

\section{Belén Monero Feduchi. Un banco sereno y ligero}

Belén Moneo Feduchi, perteneciente a una destacada saga de arquitectos (Figs. 1a y 1b), nunca ha dudado en reconocer la gran riqueza cultural aportada desde su lado materno: su abuelo, Luis Martínez-Feduchi Ruiz, trabajó como director artístico de ROLACO, firma radicada en España y especializada en mobiliario tubular de acero; su tías, Lucrecia (llamada Coti), renombrada ilustradora y Elena, directora artística de ARTESPAÑA, estuvieron ligadas al diseño; pero también su madre, Belén, que junto con Peque Lantero y posteriormente 
Luz Sánchez Muro, comandó la tienda de muebles y diseño, BD Madrid. Todos ellos han supuesto un gran refuerzo positivo en su trayectoria. ${ }^{20}$

Belén Moneo Feduchi empezó a estudiar Física en la Universidad Autónoma de Madrid durante dos años, pero la familia se traslada a Estados Unidos en 1985 y ella decide acompañarlos y empezar otra carrera, graduándose en Historia del Arte y Artes Visuales por la universidad de Harvard en 1988. Completa su formación académica con el título de arquitecta por la universidad de Columbia en 1991, allí tiene como profesor a Steven Holl y conoce a su actual socio y compañero, Jeff Brock. Una década más tarde retornarán a dicha universidad para trabajar en la construcción de los laboratorios, en calidad de arquitectos asociados a Rafael Moneo.
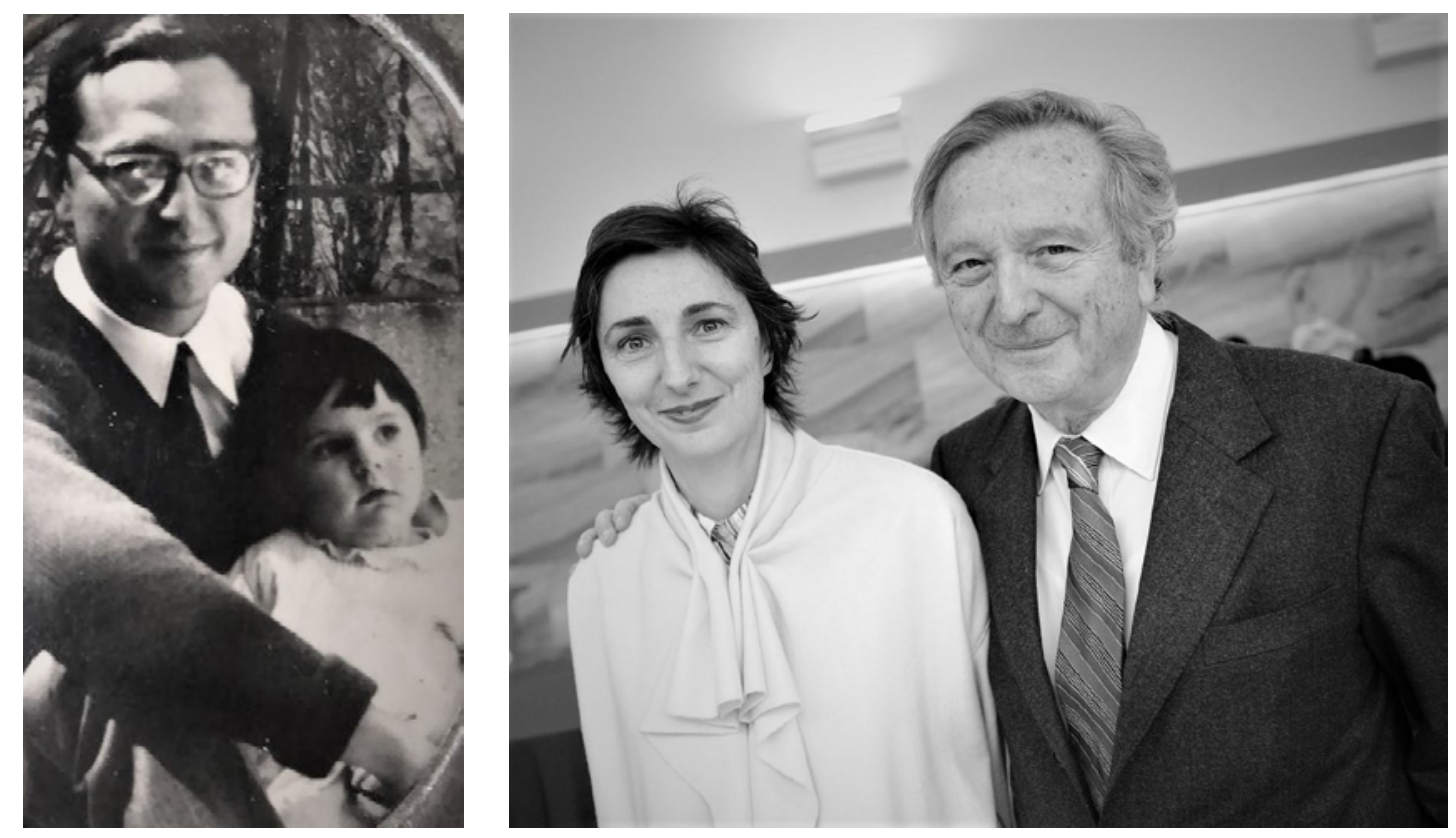

Figs. 1a y 1b. Fotografías de infancia de Belén Moneo Feduchi junto a su padre Rafael Moneo y en la actualidad. Archivo personal Moneo Feduchi.

Belén Moneo empieza su carrera profesional en un Nueva York con escasa construcción de obra nueva, pero en pleno auge de la rehabilitación y reforma integral de edificios ya existentes. El acondicionamiento de antiguos almacenes para un uso residencial, los denominados lofts, posibilitaron a Moneo-Brock diseñar integralmente los interiores: todos los muebles empotrados de cocina y baño, además de alfombras, cortinas y puertas correderas. Este arranque inicial, que les permitió deleitarse con los detalles, fue la antesala de su siguiente trabajo: los museos de Arte Moderno y Arquitectura de Estocolmo.

A mediados de la década de los noventa del siglo pasado, Belén Moneo y Jeff Brock se trasladan a Estocolmo. Rafael Moneo Vallés había ganado en 1991 el concurso para la construcción de los museos ubicados en un pequeño islote perteneciente a la armada sueca. Es en esta pequeña isla, denominada Skeppsholmen, donde trabajará el arquitecto de origen navarro como autor y director de la obra, pero también y de forma permanente en el país, Belén Moneo y Brock. Era necesaria la completa dedicación y por ello, desde su puesto de jefes 
de proyecto, estarán permanentemente en la obra, colaborando en su dirección, hasta su finalización en 1998.

Desde la cercanía y el completo conocimiento de estos espacios museísticos, les surge la posibilidad de diseñar parte del interiorismo: varias lámparas, entre las que destacan un prototipo en ménsula para la zona de entrada y una lámpara colgante con forma de cúpula, junto con los bancos de las salas. Piezas discretas y serenas, en total consonancia con un edificio que no quiere ser protagonista respecto al resto de edificaciones de la isla.
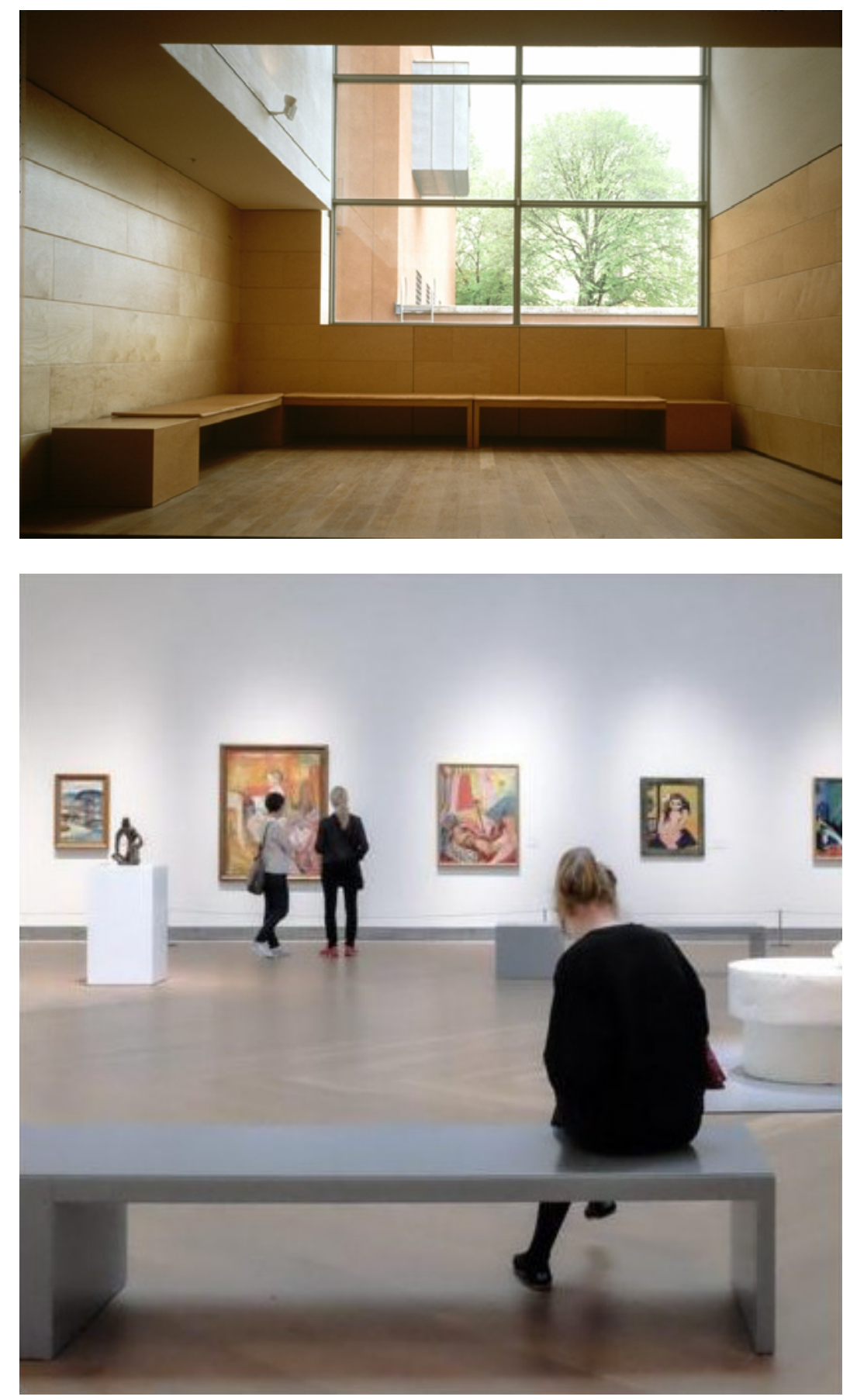

Figs. 2a y 2b. Banco diseñado por Belén Moneo y Jeff Brock para el Museo de Arte Moderno y Arquitectura en Estocolmo. Fotografías archivo Moneo-Brock 
El banco de Moneo-Brock es asimétrico, uno de los extremos se remata a modo de cajón que hace las veces de una pequeña mesa supletoria. En ella puede descansar el escaso equipaje de mano del visitante e incluso apoyar instalaciones audiovisuales (Figs. 2a y 2b). Ligereza y estabilidad, dos características que recuerdan a los muebles de la diseñadora de la Bauhaus Alma Buscher, pero muy distintos a los bancos de otro museo realizado por otra pareja de arquitectos: Robert Venturi y Denise Scott Brown para la ampliación de la National Gallery de Londres. Si bien la estructura de galerías planteada en el museo de Londres puede tener alguna similitud al planteamiento de Estocolmo ${ }^{21}$, los bancos son radicalmente opuestos. Mientras que los ideados por los estadounidenses presentan un eclecticismo historicista, los bancos de Moneo-Brock persiguen una línea de pureza y discreción. Sin tener ninguna relación formal, estos últimos sí respiran el espíritu austero de los bancos que el matrimonio finlandés Heikki y Kaija Siren emplearon para la capilla de Otaniemi (1954/57), o el ascetismo de los pensados por otra pareja, Reima y Raili Pietilä, en la iglesia de Kaleva (Tampere, 1964/66), todos ellos herederos del legado de Alvar Aalto y Aino Marsio.

El banco de Belén Moneo y Brock, a diferencia de los utilizados en estas iglesias finlandesas, carece de respaldo, esto le permite ser utilizado también para sentarse de forma transversal y copiar o tomar notas a modo de mesa. Esta idea de ofrecer la libertad de sentarte de forma no convenida retoma de nuevo la rama centroeuropea de la Bauhaus, que hacía suya la máxima estudiantil de no sentarse nunca dónde y cómo se les dice que se deben sentar. Son innumerables las fotografías del alumnado sentado, a veces con los pies colgando, en terrazas, petos y azoteas. Incluso al maestro en el taller de carpintería, Marcel Breuer, le gustaba sentar sus mesas modelo $\mathrm{C} 4$, más pequeñas aunque más altas, encina de las del modelo K4. Esta superposición no la podía pasar por alto una joven que fue dibujada por el pintor Karl Hubbuch, utilizando la mesa C4 como asiento (Figs. 3a y 3b).

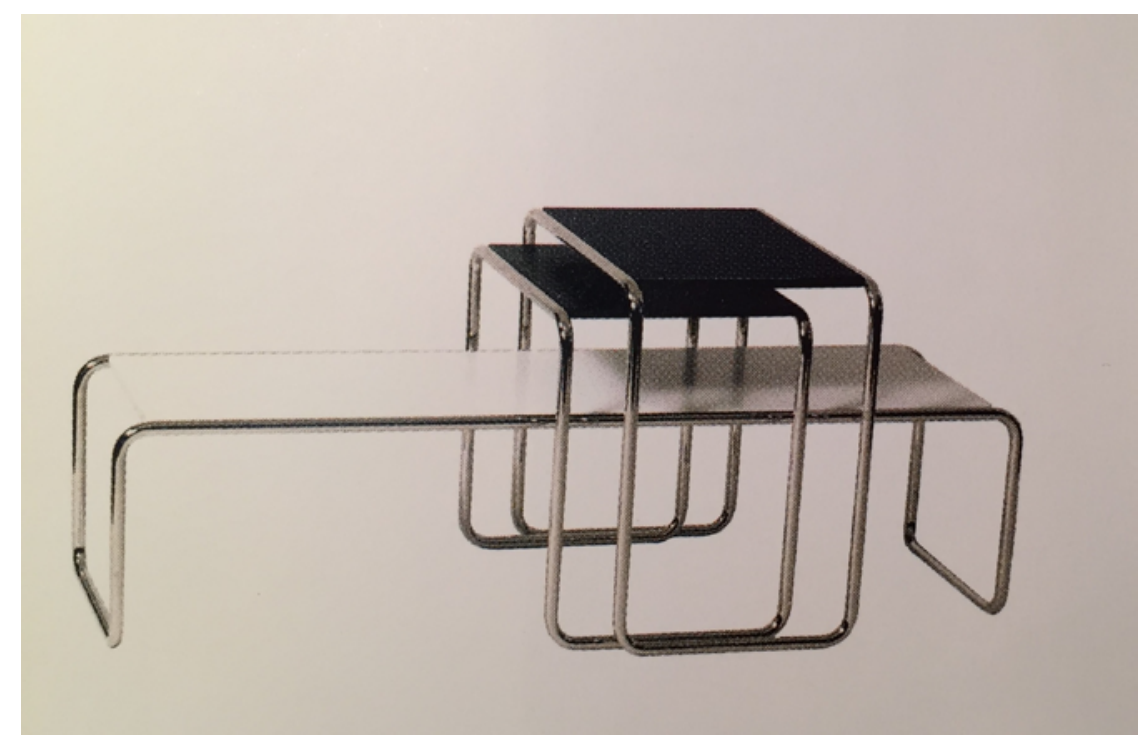

Fig. 3a. Mesas modelo C4, sobre una modelo K4, diseño de Marcel Breuer. Fotografía del catálogo TECTA 2003. 


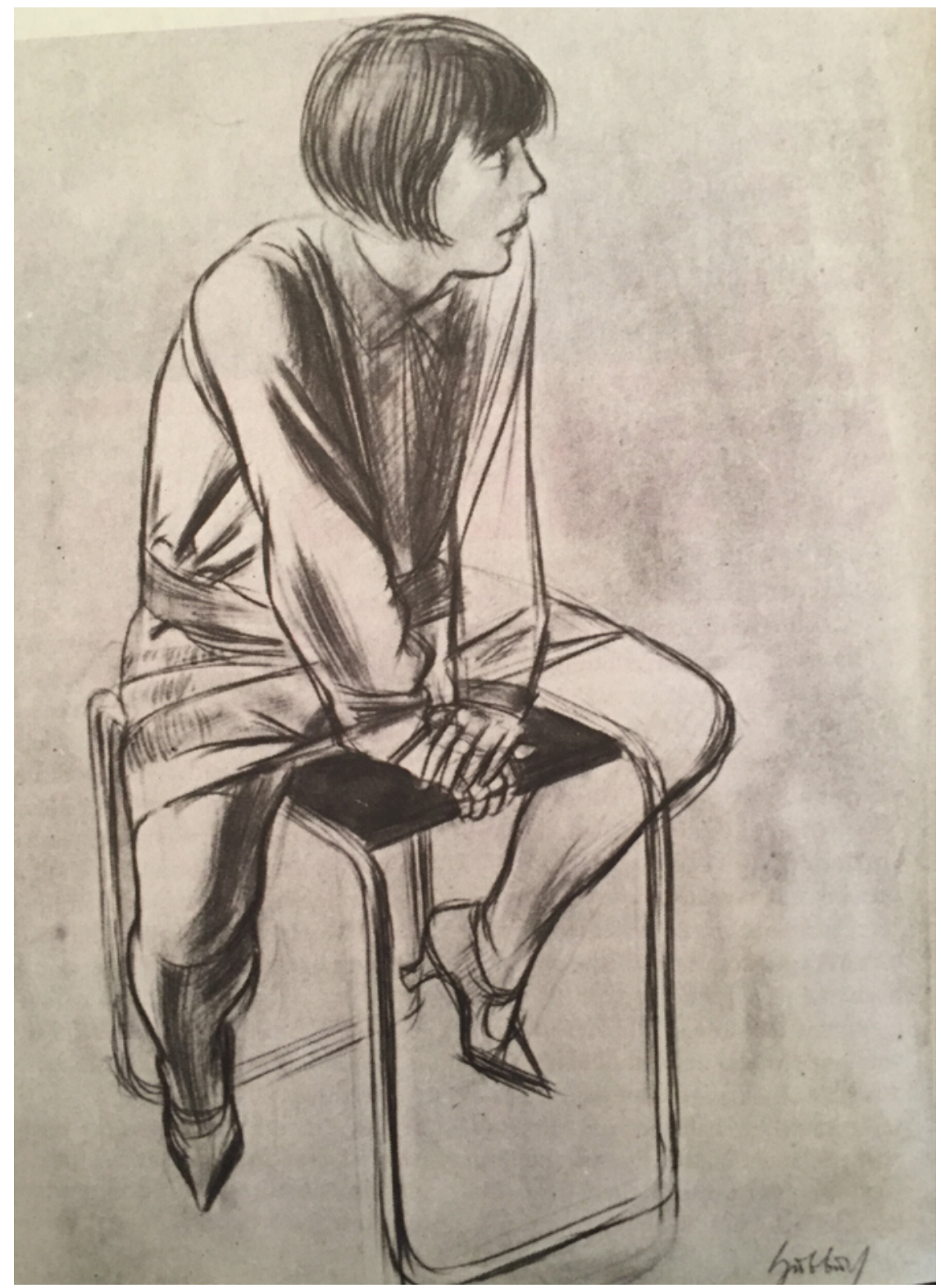

Fig. 3b. Mujer joven sobre modelo C4 dibujada por Karl Hubbuch, en Bauhaus, Die Zeitschrift der Stiftung Bauhaus Dessau, 114.

\section{Marisa Sáenz Guerra. La solidez de una silla}

Marisa Sáenz Guerra pertenece a una familia numerosa donde varios hermanos han seguido la profesión del padre, el arquitecto Francisco Javier Sáenz de Oíza (Figs. 4a y 4b). El maestro trabajó en su última etapa formando un conjunto familiar, rememorando los antiguos gremios medievales.

Marisa Sáenz Guerra se tituló como arquitecta en la Escuela Técnica Superior de Arquitectura de Madrid en 1990. Junto a sus hermanos, ha formado equipo en diversos edificios culturales diseñados por su padre. Es el caso del Centro Atlántico de Arte Moderno de Las Palmas (CAAM), o el Centro Cultural de Villaviciosa de Odón; pero es en Alzuza (Navarra), en la Fundación Museo Jorge Oteiza, donde tanto ella como su hermano Vicente ostentaron la responsabilidad de la dirección final de obra y del mobiliario realizado exprofeso. 


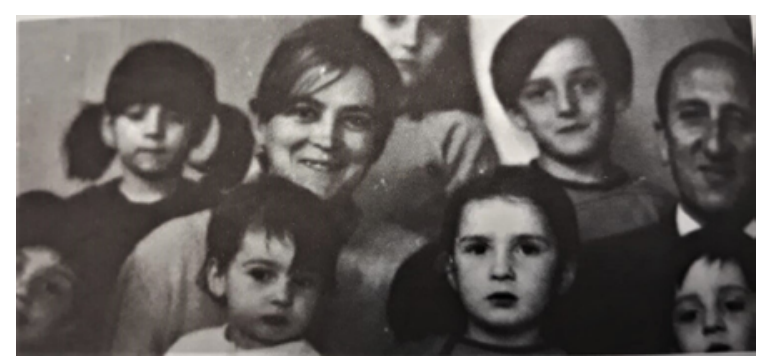

Fig. 4a. Fotografía familiar de Marisa Sáenz Guerra junto a sus padres y hermanos. Archivo personal Sáenz Guerra.

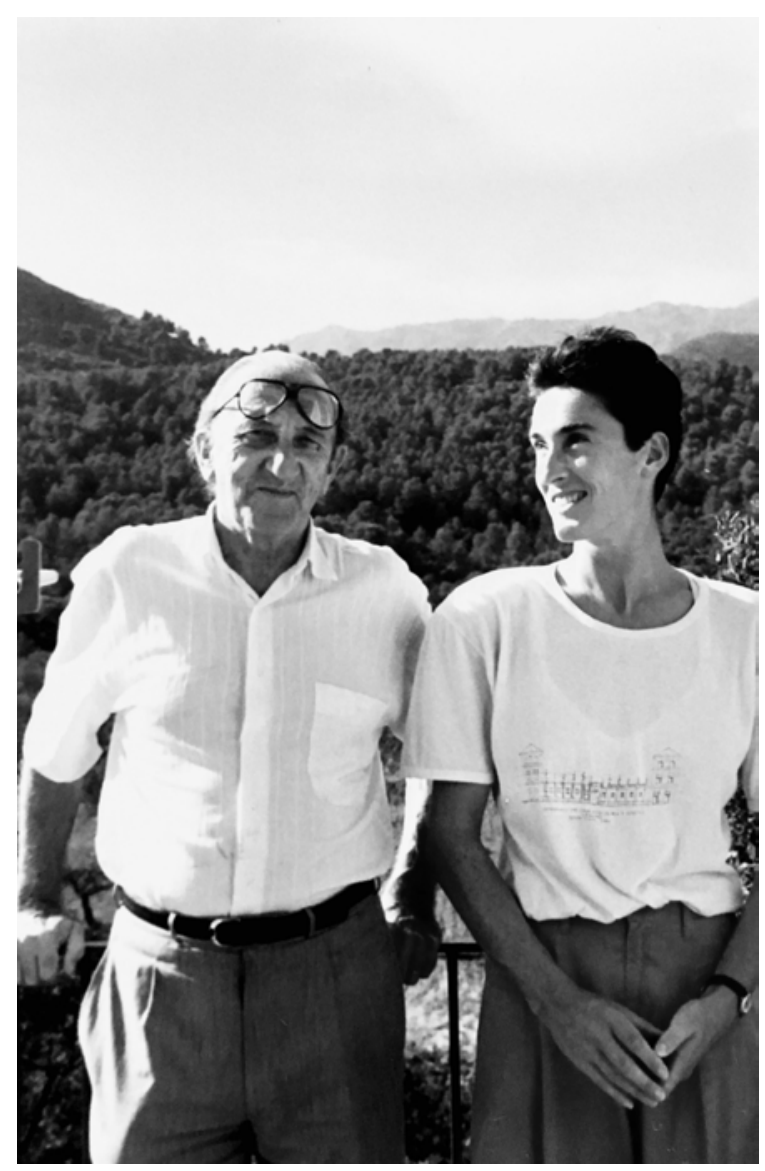

Fig. 4b. Marisa Sáenz junto a su padre Francisco Javier Sáenz de Oíza en septiembre 1989. Fotografía de Santiago Larragán.

El diseño del mobiliario para el Museo del escultor Oteiza fue para Marisa y Vicente Sáenz un reto y una oportunidad. Era necesario para el estudio de arquitectos rematar el trabajo como una unidad: el edificio y su mobiliario. Siempre había sido importante, pero en esta ocasión, las esculturas de Oteiza, el edificio-contenedor como una caja de resonancia, y la silla para el salón de actos y para la casa taller, debían guardar una completa concordancia en opinión de Marisa Sáenz. Son miles las anécdotas que esta puede relatar del trabajo conjunto, pero hay una que le sugiere especial interés y que refuerza la idea de arquitectura total que manejaban ella y su padre: 
Recuerdo cuando mi padre fue a ver el edificio que había proyectado y ejecutado en Villaviciosa de Odón; vio unos muebles horribles [...] y dijo: "O se han equivocado con el arquitecto o se han equivocado con el amueblador. ${ }^{22}$

Recordarlo es gratificante para ella. La curiosidad que mostraba su padre ante cualquier objeto de uso cotidiano y su gran conocimiento, quedan ejemplificados en el relato que Marisa Sáenz escribió en 2007, eligiendo un objeto preferido de su entorno, un objeto muy estimado por ella:

Recogimos una vez esta silla maltrecha de un contenedor, y, al desmontarla para arreglarla, vimos que no tenía más de dos tornillos, cosa sorprendente para unos montadores habituales de muebles de Ikea. Se compone de piezas ensambladas, con solo tres tipos de sección, de madera maciza y una tela de lino sencilla, que se monta como un puzzle infantil. Parece tan buena como las de Elieen Gray y de la misma época. Al verla mi padre, tras estudiarla, como hacía con todo (jugaba mucho a adivinar de cuántas piezas se componía un objeto, pensando en la habilidad de construir algo con poco número de ellas), nos dijo que pertenecía a un alumno suyo, del que no dijo el nombre, que se dedicaba a construir con ensamblaje de piezas, y que le había regalado un nudo de madera que hay en su estudio [...]. ${ }^{23}$

Toda la responsabilidad en la terminación del museo para Oteíza y en el diseño de mobiliario recayó en Marisa y Vicente; no querían de ninguna manera que ocurriese como en el Centro Cultural de Villaviciosa de Odón, pues sabían de la importancia de los detalles:

Mi padre siempre pensaba que "una pequeña intervención es transcendental para lograr una gran transformación”, ponía de ejemplo el Giraldillo: añadiendo este pequeño remate a una edificación árabe, cambiaba completamente su concepción original. El Giraldillo lo aplicó mi padre en la casa de vacaciones de Mallorca. Una especie de lucernario, que colocó en una casa tradicional, la transformó completamente. ${ }^{24}$

La Fundación Museo Jorge Oteiza, de la cual Marisa es actualmente una de sus patronos, comenzó a gestarse cuando en 1992 el escultor donó su obra para conservar y difundir su extenso legado creativo. El proyecto para el museo data de 1995 y Marisa Sáenz enfatiza lo que para ella es el espíritu del museo: una construcción espacial a base de pantallas de hormigón. Algo bidimensional y macizo, que a través de la colocación y de la apertura de huecos que permiten el juego de luces y sombras, se convierte en una caja tridimensional, en el propio museo. Francisco Javier Sáenz de Oíza, pudo apreciar toda la estructura acabada del museo, antes de fallecer en el año 2000.

La fusión entre Oíza y Oteiza debía estar presente en la creación de mobiliario para este edificio (Fig. 5). Los hermanos Sáenz no podían obviarlo y fue un claro referente la caja metafísica del escultor a la hora de concebir la silla para su Fundación. Aquí no se buscaba ligereza ni simplicidad, las características de 
la silla debían ser materialidad y estructura a base de planos, no de líneas (Fig. 6). Es por ello que la silla del arquitecto Rudolf Schindler para su casa-estudio en Kings Road, Los Angeles (1921/22), fuese un referente reconocido por la arquitecta Sáenz. ${ }^{25}$

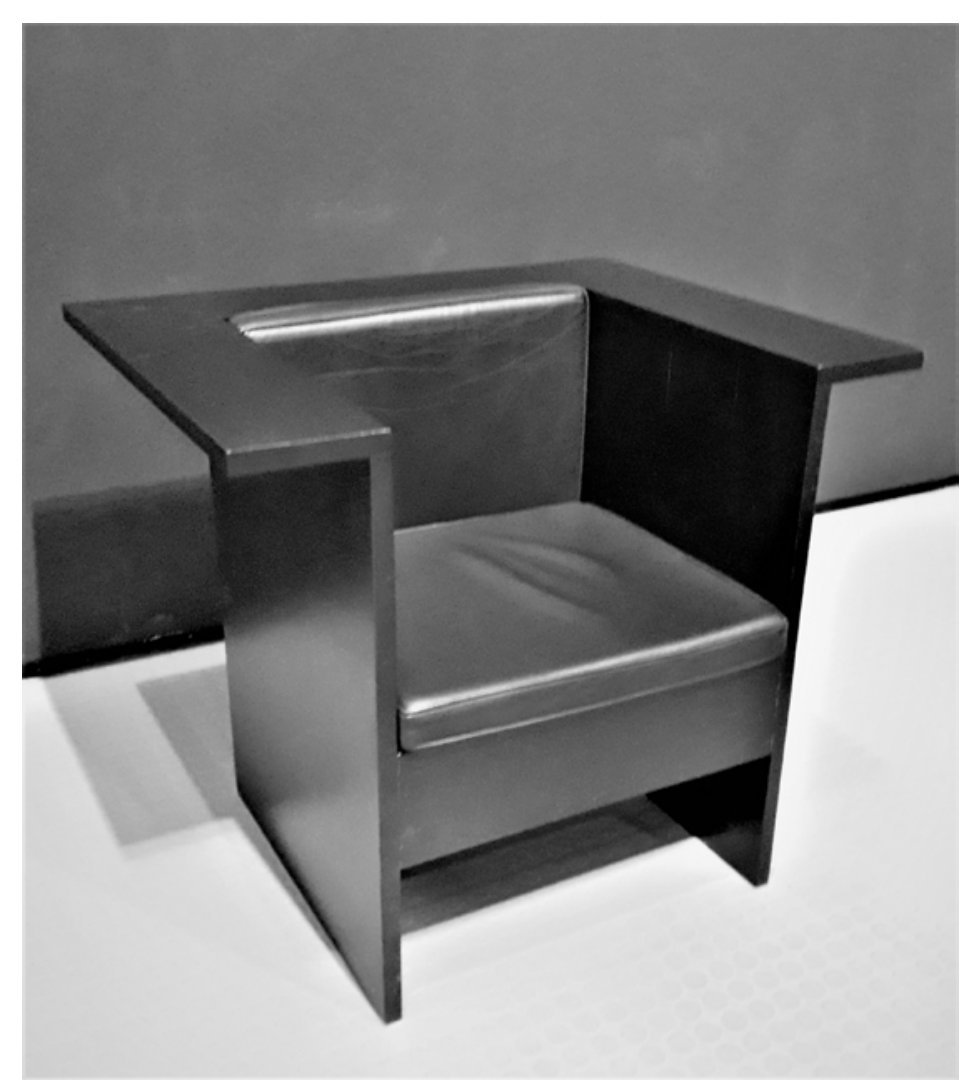

Fig. 5. Silla diseñada en 2003 por Marisa y Vicente Sáenz Guerra para el salón de actos y casa-taller de la Fundación Museo Jorge Oteiza. La silla es de madera de roble macizo teñido en color wengué. Fotografía Esteban Herrero.

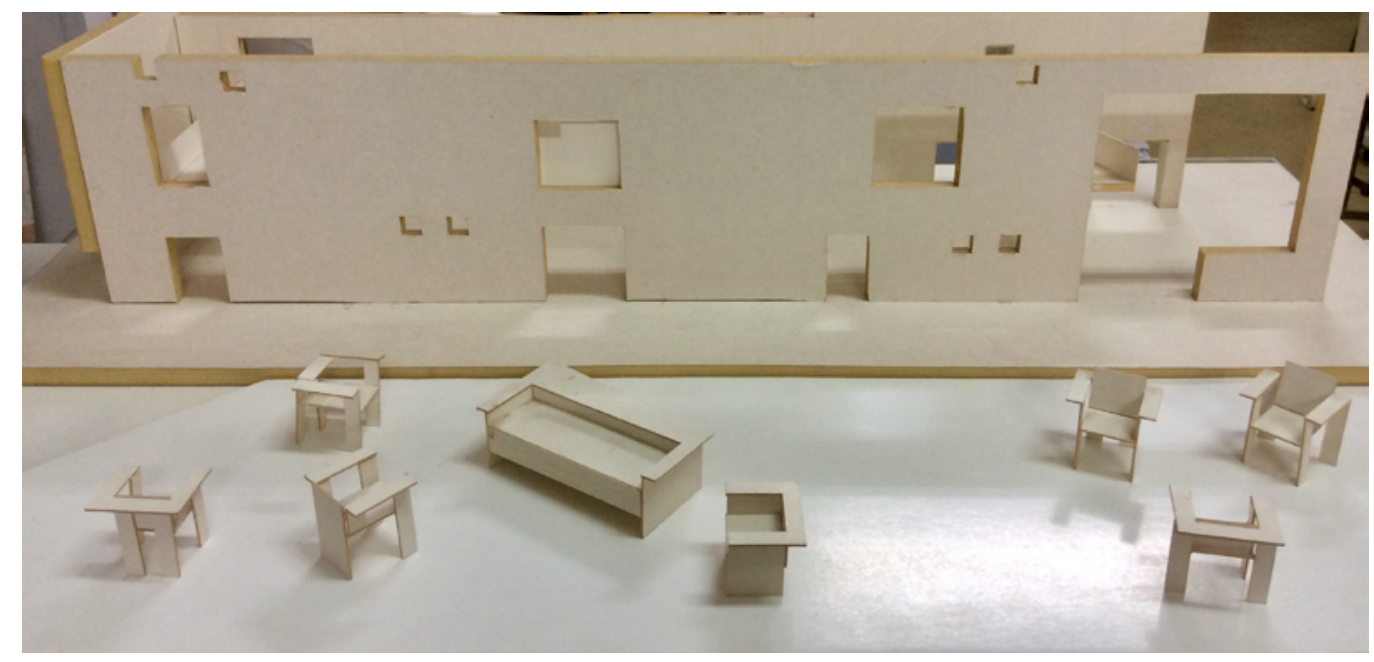

Fig. 6. Maqueta de distintas variaciones de la silla y del sillón diseñados por Marisa y Vicente Sáenz Guerra para la Fundación Museo Jorge Oteiza.

Fotografía archivo Sáenz Guerra. 
La silla de Rudolf Schindler es una silla ideada por el autor para ser utilizada por él mismo en su propia casa-estudio, realizada también con pantallas de hormigón ${ }^{26}$. Una silla con dos variantes, completamente cerrada por los laterales, o con la misma apertura lateral que lleva en el respaldo, pero tanto en un caso como en el otro inspiran sobriedad (Fig. 7). Una silla que recoge las dos líneas que atravesaron la vida de Schindler, por un lado la herencia austríaca de Adolf Loos, que promulgaba la ausencia de ornato, y por el otro, los años americanos compartidos en el estudio de Frank Lloyd Wright, al que acudió en 1917, tras dejar Europa. Es precisamente la silla de la casa-estudio de su maestro Wright en Oak Park (Chicago), un precedente de la silla de Schindler (Fig. 8). Tres sillas introspectivas que invitan al recogimiento y la reflexión, tanto en la casa-estudio de los arquitectos, como en la casa-taller del escultor.

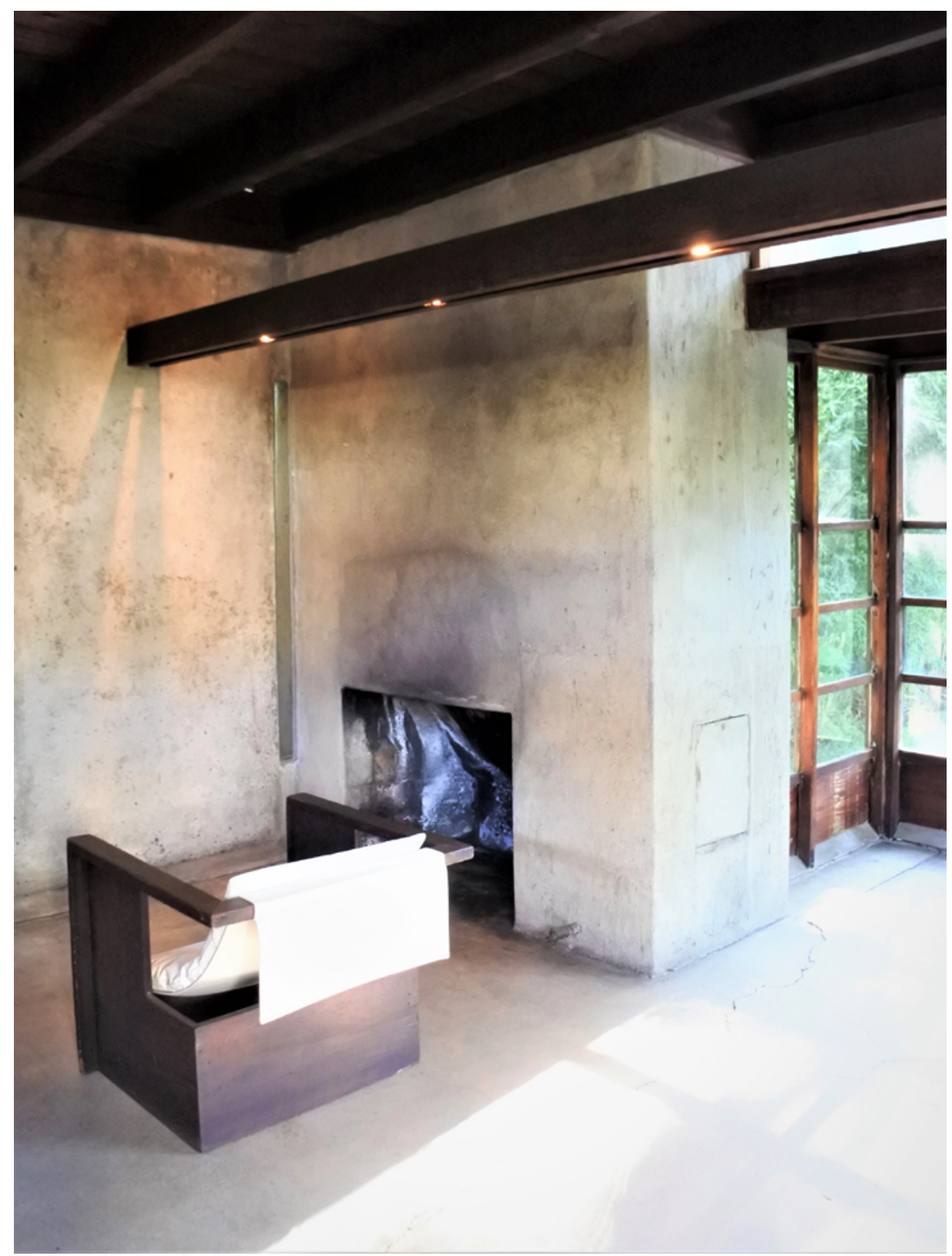

Fig. 7. Silla de Rudolf Schindler dentro de la casa-estudio Schindler-Chase en Los Angeles. Fotografía de Josenia Hervás. 


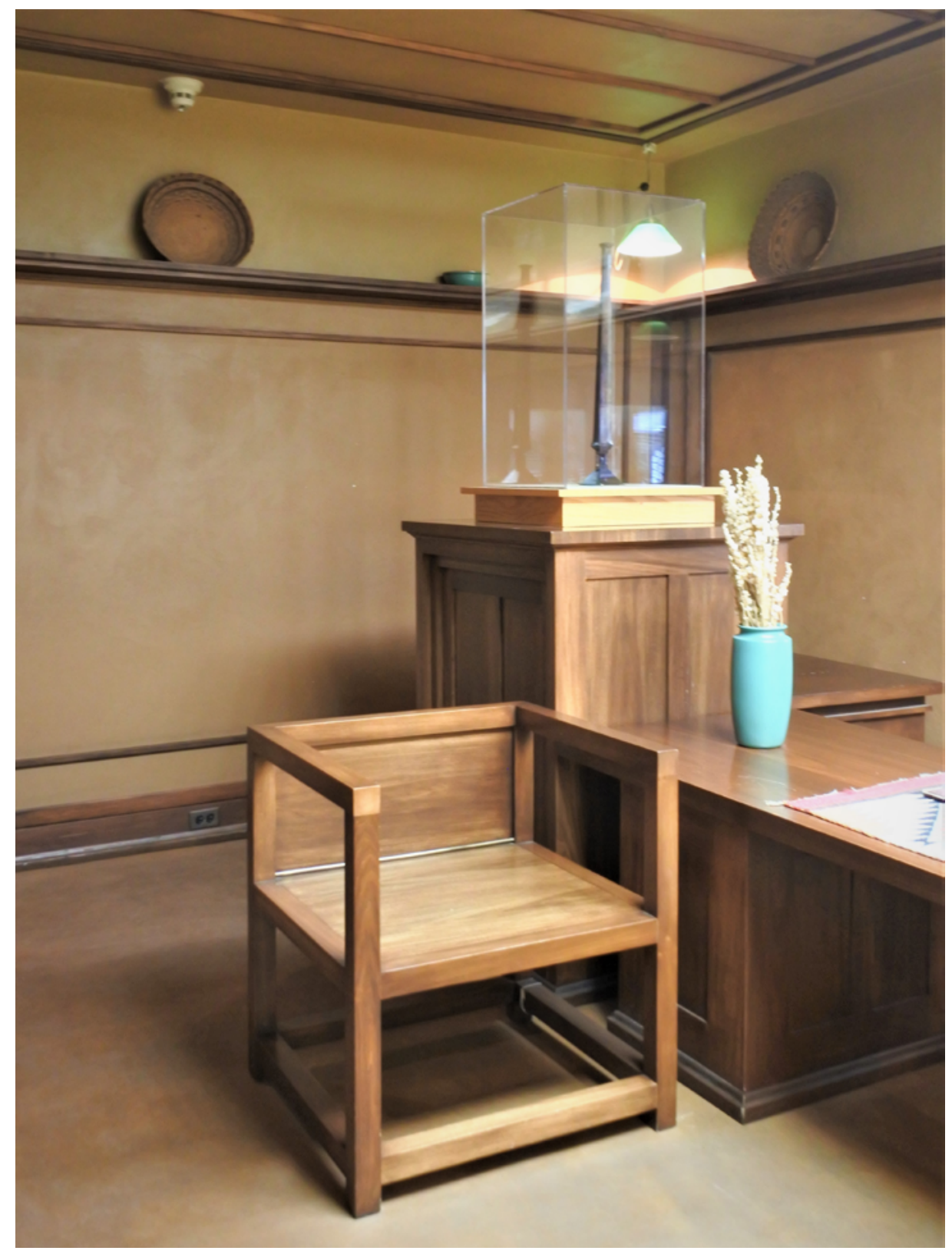

Fig. 8. Silla de Frank Lloyd Wright dentro de la casa-estudio en Oak Park (Chicago). Fotografía de Josenia Hervás.

\section{Cristina Vallejo Llopis. La silla con cuerda de esparto como antecedente}

Tras titularse en 1994 en la Escuela Técnica Superior de Arquitectura de Madrid, Cristina Vallejo ha desarrollado su actividad profesional en dos grandes campos: por un lado, en la edificación de obra nueva y rehabilitación; por otro, en el diseño de mobiliario y espacios expositivos (Fig. 9). Ha colaborado con su padre, Antonio Vallejo Acevedo, en la dirección de obra de varios edificios, como la Escuela de Hostelería de Alcalá de Henares (1991), pero su conexión más estrecha con su progenitor se halla en la silla Almería (1959), de estructura metálica, con asiento y respaldo encordado con esparto.

No era extraño que a finales de los años cincuenta, los arquitectos diseñasen piezas de pequeña escala y experimentasen con las diferentes técnicas de 
construcción de mobiliario. En palabras de Antonio Vallejo: "En aquella época, todo arquitecto tenía una silla y yo quise diseñar la mía" ${ }^{27}$. Tan solo dos años después de haberse titulado, el resultado de ese anhelo fue una estructura en tubo calibrado de hierro de 12 milímetros de diámetro, lacada en negro, con asiento y respaldo encordado de esparto. Los primeros ejemplares fueron realizados en 1959 en el taller de cerrajería de Miguel Algarra Salas de la calle de la Fragua, en Almería, completados con el trabajo de una familia de encordadores de La Chanca, Almería. Si bien los primeros doce modelos presentaban todavía algunos titubeos debido a la premura del pedido ${ }^{28}$, los siguientes ya fueron optimizados y elaborados por la fábrica Plásticos Durex, en Salamanca, donde se desarrollarían también diseños de mobiliario de algunos, por aquel entonces jóvenes arquitectos, como Fernando Ramón Moliner.

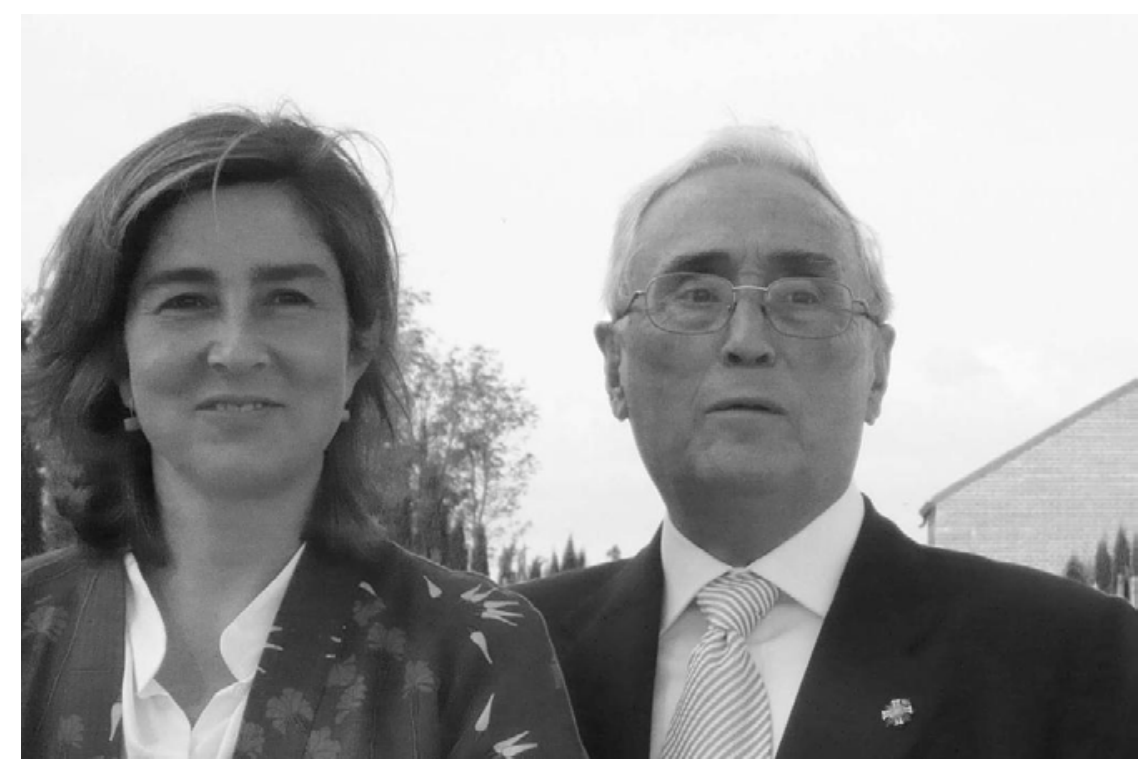

Fig. 9. Cristina Vallejo Llopis junto a su padre Antonio Vallejo Acevedo. Fotografía archivo personal Vallejo Llopis.

Tejer la trama de hilos fue un objetivo perseguido por muchos otros diseñadores durante la década de los cincuenta, de modo que sus creaciones compartiesen una imagen icónica de delicada apariencia. Se trataba de dar una nueva estética a materiales cotidianos sin perder de vista la comodidad, la resistencia y la durabilidad. La silla Acapulco, de diseño anónimo a base de tubulares metálicos y fibras naturales, surgió en las costas mexicanas en esa misma década. La Butaque de Clara Porset, en su versión tejida, reinó entre otras, en la casa Gálvez, que Luis Barragán terminó de construir en 1955 en el Distrito Federal. Atractivas e intercambiables para distintos ambientes domésticos, flexibles en cuanto a su uso en diferentes climas, la colección de diseños icónicos se completa con la Cord Chair, creada en 1953 por Jacques Guillon, referencia en el diseño industrial canadiense; la Side Chair, ideada por el estadounidense Allan Gould en 1952; o la CH25 del danés Hans J. Wegner, comenzada a producir a partir de 1950. Precedentes de todas las anteriores, la silla Weissenhof, diseñada en 1927 por Ludwig Mies van der Rohe y Lilly Reich, que fue la responsable de la 
incorporación de la urdimbre textil a las líneas curvas de la estructura metálica. En continuidad con las propuestas de Mart Stam, dicha silla formó parte de algunas de las obras más relevantes de la arquitectura moderna. ${ }^{29}$

Con relación a la silla Almería, comentar que esta fue empleada en diferentes proyectos del arquitecto, y amuebló también la casa levantina en la que toda su familia pasaba los veranos. De esta última ubicación, se conservaron cuatro ejemplares que hace una década, aprovechando una mudanza, se procedieron a recuperar. Tenían el encordado deteriorado, después de muchos años de uso, pero el componente sentimental no había variado. Hay que señalar que una de las fotografías de época muestra a su hija, todavía una niña, observando a la cámara a través del espacio que queda entre el respaldo y el asiento de la silla (Figs. 10a y 10b). Solo su cara enmarcada por el encordado de esparto. No es de extrañar pues que el hecho de ceñir con cuerdas haya sido clave para propuestas posteriores de Cristina Vallejo, que comercializa desde 2014 bajo la marca EL SUR. Bajo dicha editora de mobiliario y productos, esta arquitecta se dedica al desarrollo de objetos cotidianos que exploren nuevas formas y materiales, borrando la línea entre artesanía e industria. El encordado paterno fue la clave para sus diseños propios de bancadas:

En aquella época, estaba empezando a poner en marcha ELSUR, una editora de mobiliario y de producto con la que quería desarrollar diseños contemporáneos que incorporaran oficios tradicionales de España. En mi búsqueda de esos oficios, conocí a Carlos Fontales, investigador, docente y divulgador de trabajos con fibras naturales. Aquella fotografía me vino a la cabeza. Qué perfecta ocasión para aprender con él a encordar asientos y ser yo quien trabajase sobre esas cuatro sillas diseñadas por mi padre y que recordaba desde mi infancia.

Me apunté a un curso de iniciación al encordado que impartía en Caballar, Segovia. Esos días intensos de aprendizaje, me sirvieron también para redescubrir el mueble sobre el que estaba trabajando. Un mueble de siempre, fácil de mover de un sitio a otro y con más usos posibles que el de sentarse, la banqueta con asiento de enea.

Seguí profundizando en técnicas de encordado por mi cuenta y después de restaurar las cuatro sillas Almería, utilizando cuerda de cáñamo en vez de esparto, me planteé diseñar una banqueta que propusiera una revisión de la tradicional. Así surge el banco C1. La C que da nombre a los bancos viene de "Caballar" en homenaje, silencioso, a Carlos Fontales.

Cristina Vallejo Llopis es la tercera generación de arquitectos de la familia. El abuelo y el padre también trabajaron juntos. Antonio Vallejo Álvarez y Antonio Vallejo Acevedo colaboraron en el colegio Sagrada Familia de Valladolid, un equipamiento docente y religioso caracterizado por la modulación, la investigación en el empleo de hormigón visto y el cuidado en el diseño de los detalles..$^{30}$ Interesada en la relación entre el ser humano y los objetos cotidianos, Cristina Vallejo trabaja hoy en día cerca de los diseños que exploren nuevas posibilidades de uso y componentes. Colabora con profesionales locales, 
lo que le permite seguir de cerca todo el proceso en el que desea poner en valor la selección de los materiales, los detalles, la cercanía al entorno y la habilidad técnica, para ofrecer objetos singulares (Figs. 11a y 11b), pero cuyas huellas paternas son plenamente reconocibles.

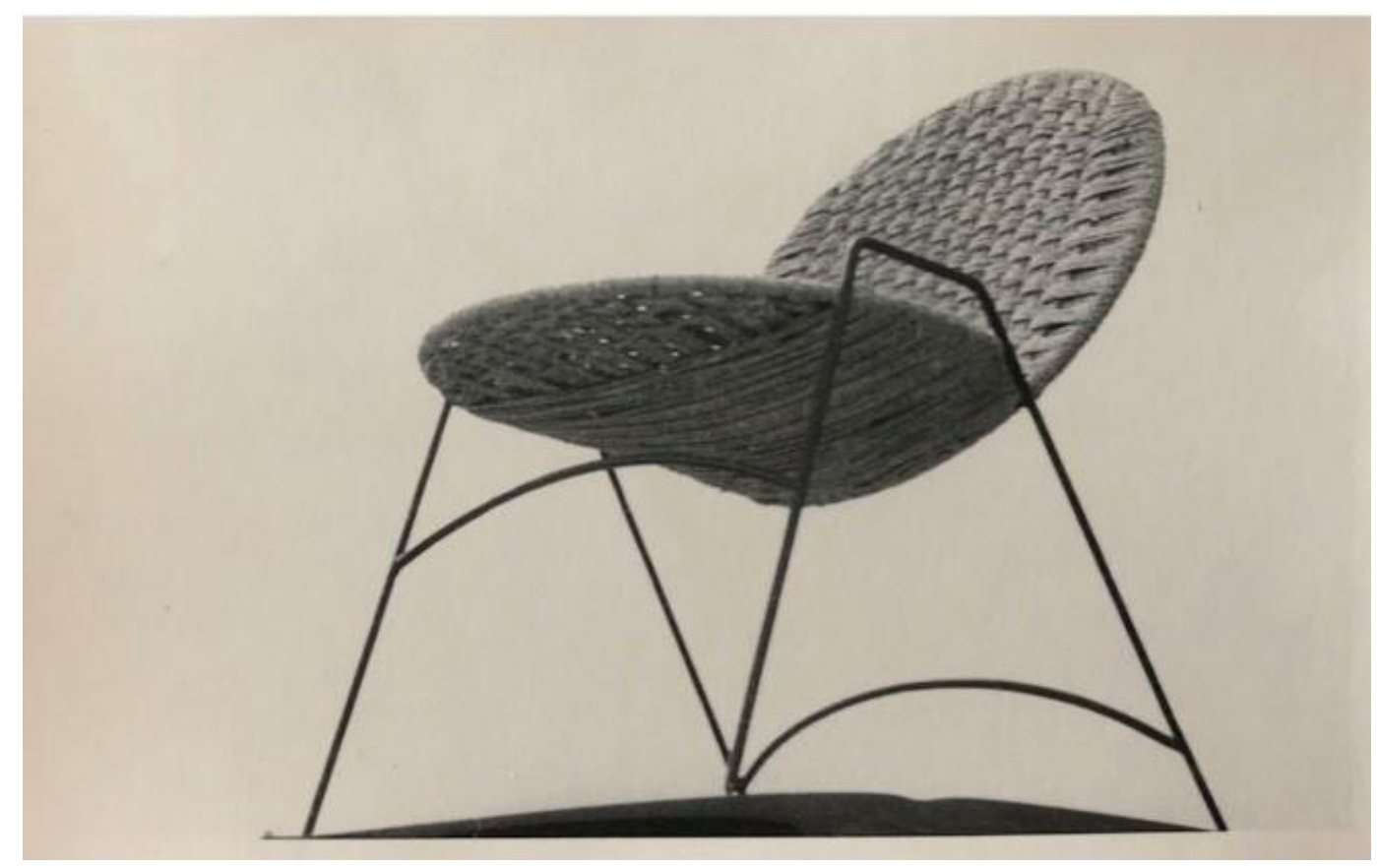

Fig. 10a. Silla Almería, diseñada en 1959 por Antonio Vallejo Acevedo. Estructura de tubo de hierro calibrado de $12 \mathrm{~mm}$ lacado en negro y con asiento y respaldo encordado con esparto.

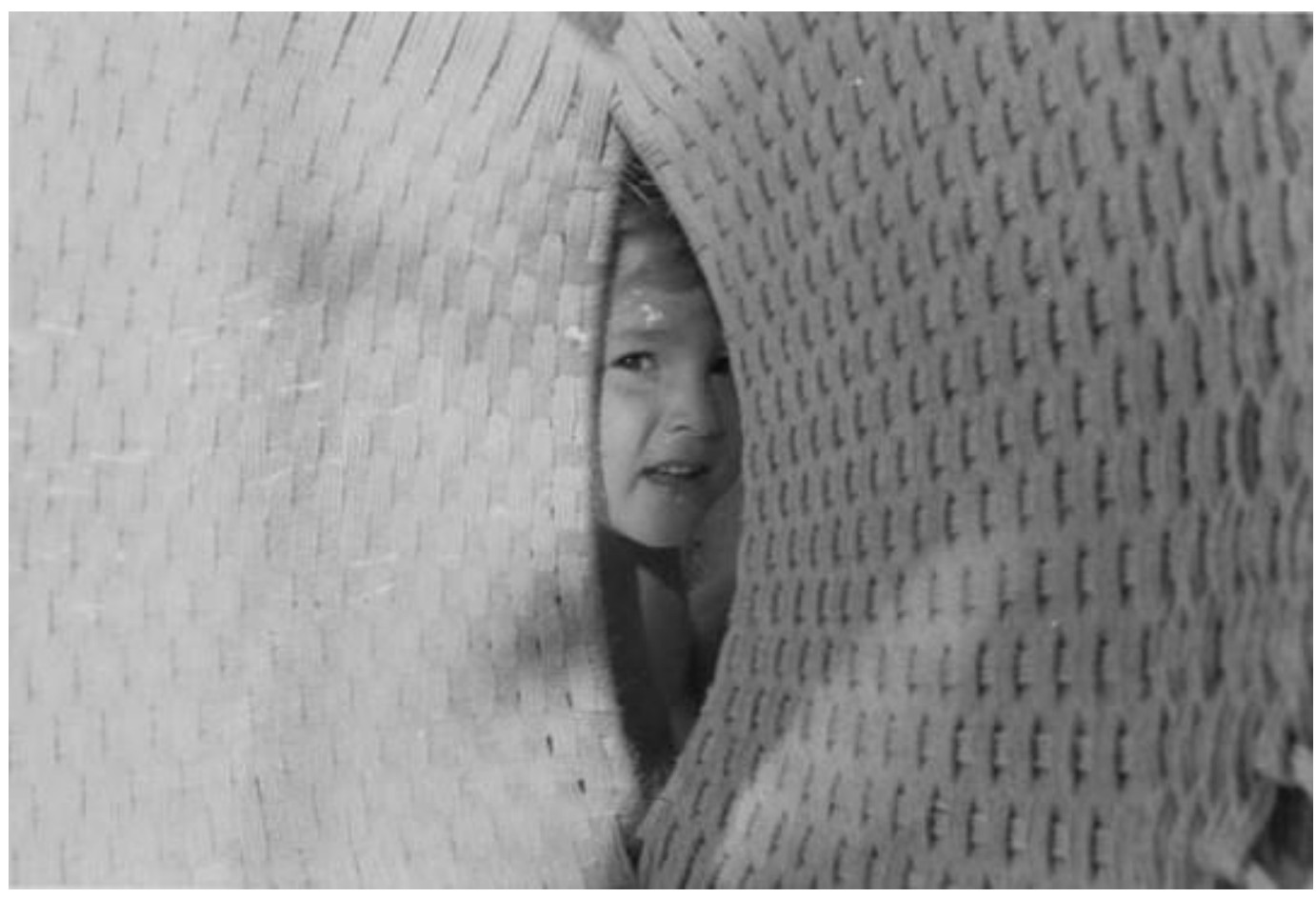

Fig. 10b. Cristina Vallejo de niña, mirando a través de la silla Almería, 1969. Fotografías archivo personal Vallejo Llopis. 


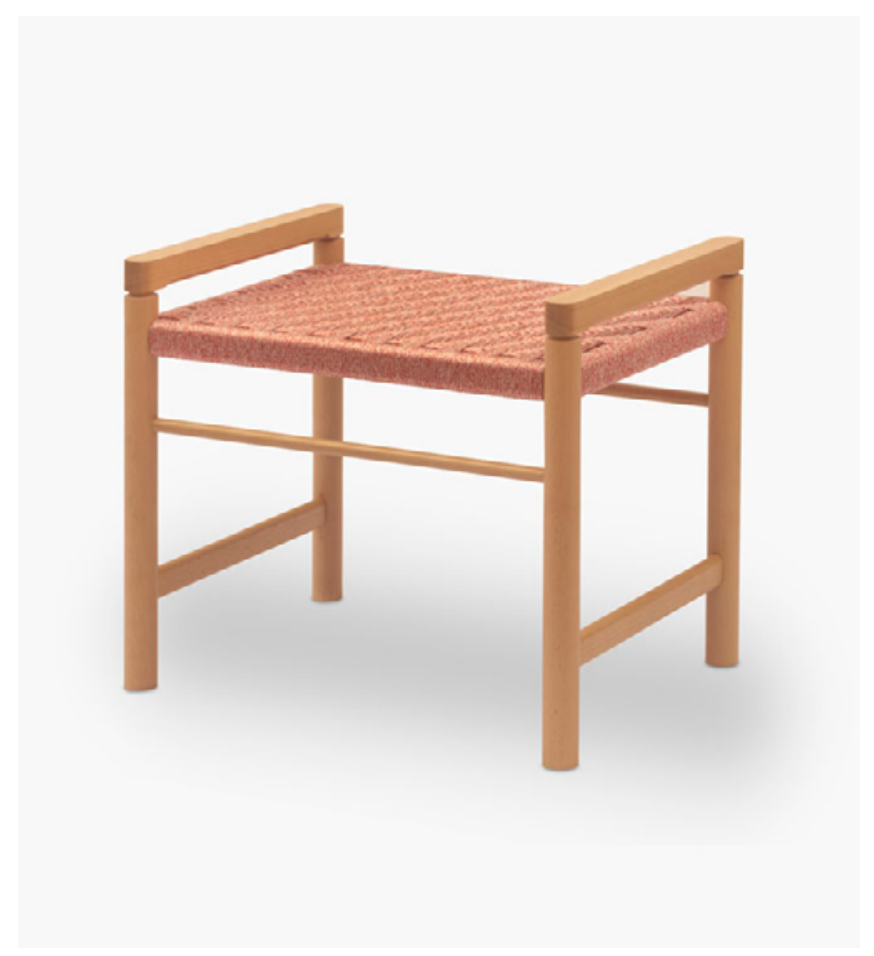

Fig. 11a. Banco C-1 (2014), creado por Cristina Vallejo.

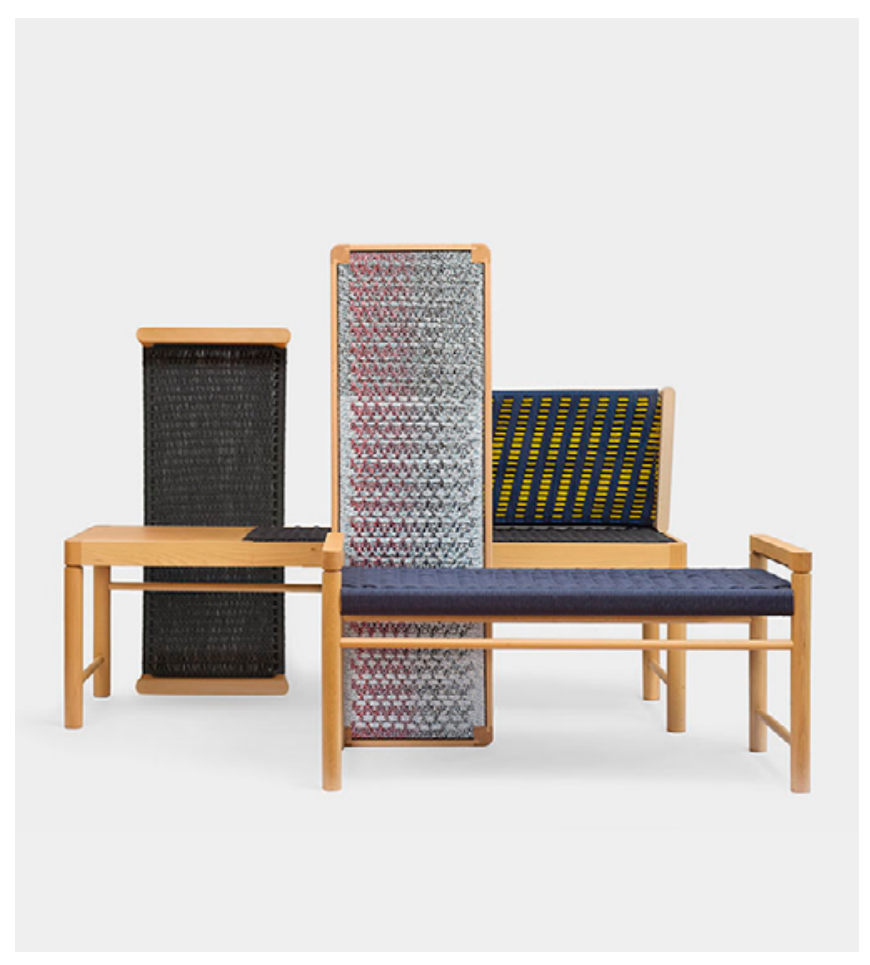

Fig. 11b. Variaciones del banco C-2 (2015), creado por Cristina Vallejo. Realiza siempre de forma continua la urdimbre y la trama. Ella juega con el efecto sorpresa, sus bobinas llevan cuerdas con mezcla de hilos de diferentes colores, de manera que hasta que no va realizando el encordado, no conoce el resultado cromático final. Fotografías archivo personal Vallejo Llopis. 


\section{Conclusiones}

Inicialmente las mujeres se incorporaron al mundo del diseño de mobiliario y a la arquitectura de forma tangencial. Como en tantas otras profesiones, se las consideró "una compañera del hombre", una ayuda o un refuerzo para él. La labor creadora, la capacidad de abstracción o el genio artístico, no eran cualidades atribuibles al género femenino hasta bien entrado el siglo XX.

En España, los planes de desarrollo y la industrialización de los años sesenta del siglo pasado, requerían una cantidad ingente de técnicos y diplomados para un país que crecía y aglutinaba su población en torno a las grandes ciudades. A partir de los años sesenta, un número considerable de mujeres, aunque discreto con relación a sus compañeros, ingresaron en las universidades españolas ${ }^{31}$. Mientras que los arquitectos se dedicaron mayoritariamente al desarrollo libre de una profesión que contaba con reservas de actividad, las arquitectas - aun siendo muchas menos - optaron fundamentalmente por la docencia, el trabajo en organismos públicos o colaborando en estudios con otros colegas, de manera que quedaron prácticamente al margen del diseño de productos, desarrollo que sí acometieron los arquitectos varones, como una extensión más de su profesión.

Por tanto, en las décadas de los años sesenta y setenta, la mayor parte del diseño de mobiliario estaba realizado por arquitectos varones o colectivos de profesionales en los que se encontraba algún arquitecto. Sin embargo, las primeras diseñadoras españolas que alcanzan notoriedad en España, lo hacen fundamentalmente en el diseño textil, gráfico o de interiores.

Cuando el diseño industrial no se había introducido mayoritariamente en el currículo de las escuelas de interiorismo o diseño, contar en el ámbito familiar o cercano con las herramientas y el bagaje para ahondar en la cultura del desarrollo de un producto, fue fundamental para que algunas mujeres realizaran una inmersión en este campo.

Las tres arquitectas españolas estudiadas en este artículo nacieron en la década de los años sesenta, años de fuerte desarrollo industrial en España. Crecieron teniendo junto a ellas a progenitores que diseñaban muebles y edificios. A su alrededor y a su disposición contemplaron libros, maquetas, planos o prototipos de objetos. Esos escenarios comunes compartidos por las tres arquitectas incentivaron e impulsaron su curiosidad y su afán creativo. Asimismo, el hecho de los referentes femeninos en el ámbito de la divulgación, difusión y comercialización de piezas singulares de mobiliario, contribuyó también a que ellas mismas hayan apostado por la creatividad aplicada a una menor escala.

A través de su formación académica y su experiencia, estas tres arquitectas trabajan en el diseño de mobiliario de forma profesional. En el caso de Marisa Sáenz de forma esporádica, asientos o estanterías. En el caso de Belén Moneo, con una gama de productos en el mercado que ofrece sillas, alfombras, estanterías, lámparas o mamparas separadoras. Cristina Vallejo, desde su marca EL SUR, tiene en la actualidad plena dedicación y nos ofrece una gran variedad de tejidos realizados por ella misma, dando forma a vasijas textiles, alfombras, mantas, bandejas de piedra natural o asientos, como la butaca RSC —reinterpretación de la silla Roorkhee_-, sin olvidar sus bancos de urdimbre. 
Las tres arquitectas objeto de estudio han trazado sus trayectorias otorgando una relevancia especial al proceso creativo situado entre el arte y la industria, han mostrado un gran interés por la estética y por la investigación aplicada a los objetos cotidianos, tanto desde el empleo de geometrías de mínimos irreductibles, como desde el confort y la funcionalidad. Han pasado de ser usuarias del mobiliario y de las edificaciones paternas a ser la siguiente generación que toma el testigo.

\section{NOTAS}

${ }^{1}$ Josenia Hervás y Silvia Blanco-Agüeira, "Women Architects outside the Spanish Borders: Patriarchal Models at International Congresses (1939-1975)," Arts 9 no. 1 (2020): 26. https:// doi.org/10.3390/arts9010026

${ }^{2}$ Luis María Cabello Lapiedra, "El X Congreso Internacional de Arquitectos," Arquitectura 43 (1922): 426.

${ }^{3}$ Campí Valls, Isabel. "Las diseñadoras en España, 1945-2000," en Nientedimeno/Nothing less, 1945-2000-La forza del design femminile, editado por Anty Pansera y Mariateresa Chirico. Torino: Allemandi, 2011.

${ }^{4}$ Lluís Pacheco, "Elisava, la casa del diseño," El Periódico de Catalunya, 11 de mayo de 2016. Disponible en: https://www.elperiodico.com/es/barcelona/20160511/historia-escuela-elisava-rambla-ciutat-vella-5123065 [7/2/2021]

${ }^{5}$ Entrevista realizada por las autoras el 29 de enero de 2021.

${ }^{6}$ Juan Ramón Sánchez del Peral, "Las señoras copiantas. Mujeres con pinceles en el Museo del Prado del siglo XIX," en Invitadas, editado por Carlos G. Navarro (Madrid: Museo Nacional del Prado, 2020), 291.

${ }^{7}$ Hajo Düchting, Delaunay (Colonia: Taschen, 1994), 62.

${ }^{8}$ Entrevista realizada por las autoras a Lola Castelló el 29 de enero de 2021.

${ }^{9}$ Nina Masó comentaba que se optó por colocar los apellidos maternos de sus compañeros porque eran más sonoros y singulares. Presentación del libro Bauhäus Models el 15 de enero de 2020 en Madrid, dentro del ciclo "Mujer X Mujer/Woman X Woman. Obras de Diseño en Transición" (_2B space to be).

${ }^{10}$ Christoper Long, "Ornament, Crime, Myth, and Meaning2," en Architecture: Material and Imagined, editado por John K. Edwards (Washington: ACSA Press, 1997), 440-45. "Loos criticó todo, desde teteras hasta zapatos, y descubrió que el adorno del diseño es criminal, primitivo, degenerado y, lo más importante, erótico y femenino" (traducción de las autoras).

${ }^{11}$ Información facilitada en la exposición "H muebles. Entre la industria, la arquitectura y el arte", celebrada en el COAM de febrero a julio 2020 y comisariada por Pedro Feduchi, Pedro Reula y Patricia Molíns.

12 "Pasión por la belleza. Fragmentos de una conversación entre Juan Huarte y Marisa Sáenz," Pasajes de arquitectura y crítica, 20 (2000): 19.

${ }^{13}$ El jurado estaba compuesto por los arquitectos José Antonio Coderch, Ramón Vázquez Molezún y Francisco Javier Sáenz de Oíza, y por Juan Huarte y Gregorio Vicente, en representación de H Muebles.

${ }^{14}$ Isabel (Peque) Lantero, casada con el arquitecto José Antonio Corrales, estuvo al frente de bd Madrid junto con Belén Feduchi desde el inicio, según entrevista efectuada por las autoras a Belén Feduchi el 21 de febrero de 2020. Como socios aparecían unos jóvenes Javier Feduchi, Rafael Moneo, José Antonio Corrales, Elías Torres y Elías Querejeta. 
${ }^{15}$ Ignacio Zafra, "Marisa Gallén, pionera de la modernidad, Premio Nacional de Diseño," El País, 12 de noviembre de 2016. Disponible en: https://elpais.com/cultura/2019/11/12/actualidad/1573568215_659297.html [Consultado: 7/2/2021]

${ }^{16}$ Entrevista a Carlos Bento Company efectuada por las autoras el 08 de febrero de 2021.

${ }^{17}$ Paula Ramírez Jimeno, "Las pioneras el diseño industrial en España," $i+$ Diseño: revista internacional de investigación, innovación y desarrollo en diseño 9, no. 9 (2014): 81-94.

${ }^{18}$ Entrevista de las autoras con Sofía Rodríguez Bernis el 7 de febrero de 2021.

${ }^{19}$ Ana María Fernández García, "On Women Architects. Looking for a Room of One’s Own: on the Visibility of Professional Women and Associationism in Europe," en MoMoWo. 100 Works in 100 Years (Ljubljana-Turin: France Stele Institute of Art History, 2016), 16-19.

${ }^{20}$ Entrevista realizada a Belén Feduchi y Belén Moneo el 21 de febrero de 2020.

21 "Tras las huellas de Aalto: museos de arte moderno y de arquitectura, Estocolmo, 1991 (Suecia)," Arquitectura 315(1998): 60.

${ }^{22}$ Entrevista realizada a Marisa Sáenz Guerra el 6 de marzo de 2020.

${ }^{23}$ Belén Feduchi Benlliure, Luz Sánchez Muro y Elías Torres Tur, Estimados Objetos (Madrid: b.d, 2007), 162 .

${ }^{24}$ Entrevista realizada a Marisa Sáenz Guerra el 6 de marzo de 2020.

${ }^{25}$ Ibídem.

${ }^{26}$ Denominada casa Schindler-Chase. En una construcción dividida en distintas zonas, con varios espacios exteriores-interiores para el matrimonio Schindler y otros similares para el ingeniero Clyde Chase y su pareja.

${ }^{27}$ Entrevista realizada a Cristina Vallejo Llopis el 4 de marzo de 2020.

${ }^{28}$ Debían ser incorporadas con urgencia a un bar madrileño diseñado por el arquitecto. El resto de la producción formó parte de otros proyectos, como por ejemplo, el amueblamiento de unas viviendas para jóvenes en la calle Narváez de Madrid.

${ }^{29}$ La silla Weissenhof (también conocida como MR10 y MR20), formó parte del equipamiento de las viviendas que Mies van der Rohe construyó en la Weissenhofsiedlung (1927), de la villa Tugendhat (1928) y de la casa Farnswort (1951).

${ }^{30}$ Antonio Vallejo Álvarez, Fernando Ramírez de Dampierre y Antonio Vallejo Acevedo, "Colegio de la Sagrada Familia en Valladolid," Arquitectura 74 (1965): 27-34.

${ }^{31}$ El nuevo Plan de Estudios de 1964 permitió que en la Escuela Técnica Superior de Arquitectura de Madrid se matricularan ese mismo año 12 alumnas frente a un total de 207 estudiantes de la 122 promoción. Información facilitada por la arquitecta Ana Iglesias Gonzalez, graduada en el curso 1973/74 por la ETSAM. 